\title{
Metoclopramida y dexametasona para la prevención de las náuseas y vómitos postoperatorios
}

\author{
Methoclopramide and dexamethasone for postoperative vomiting prevention
}

Wallenborn J y col. BMJ 2006;333:324

\section{Objetivo}

Determinar si la administración intraoperatoria de metoclopramida combinada con $8 \mathrm{mg}$ de dexametasona tiene mayor eficacia en la prevención de las náuseas y vómitos en comparación con dexametasona sola, evaluando los beneficios y reacciones adversas.

\section{Diseño}

Estudio multicéntrico, aleatorizado, controlado con placebo y doble ciego.

\section{Lugar}

Departamento de Anestesiología y Cuidados Intensivos, Universidad de Leipzig, Alemania.

\section{Pacientes}

3140 pacientes sometidos a cirugía con anestesia regional o balanceada.

\section{Intervención}

En cada paciente se administró la medicación asignada 30 a 60 minutos antes de finalizar la cirugía o inmediatamente finalizada la misma. Ante náuseas y/o vómitos se indicó dolasetrón $(12,5 \mathrm{mg})$ ó dimenhidrinato $(62 \mathrm{mg})$.

\section{Medición de resultados principales}

Náuseas y vómitos durante las $24 \mathrm{~h}$ posquirúrgicas (desenlace primario) y reacciones adversas.

\section{Resultados principales}

La medicación con metoclopramida redujo la incidencia de náuseas y vómitos postoperatorios (NVPO) con claro efecto dosis respuesta según la dosis recibida. Ver tabla 1. Respecto de los efectos adversos, la metoclopramida se asoció a hipotensión y taquicardia durante la cirugía; y con síntomas extrapiramidales, diskinesia y alteración de los sentidos del gusto y olfato, durante el período postoperatorio.

Tabla 1: resultados principales y efectos adversos de los pacientes tratados con $8 \mathrm{mg}$ dexametasona y diferentes dosis de metoclopramida.

\begin{tabular}{l|c|c|c|c}
$\begin{array}{l}\text { Incidencia en cada grupo } \\
\text { según la dosis de } \\
\text { metocionramida asignada }\end{array}$ & $\begin{array}{c}\mathbf{0 m g} \\
(\mathbf{n}=788)\end{array}$ & $\begin{array}{c}\mathbf{1 0 m g} \\
(\mathbf{n = 7 8 3 )}\end{array}$ & $\begin{array}{c}\mathbf{2 5 m g} \\
(\mathbf{n}=\mathbf{7 8 1})\end{array}$ & $\begin{array}{c}\mathbf{5 0 m g} \\
(\mathbf{n = 7 8 8 )}\end{array}$ \\
$\begin{array}{l}\text { Náuseas y v mitos } \\
\text { postoperatorios (IC95\%) }\end{array}$ & $\begin{array}{c}23,1 \% \\
(20,2 \text { a } 26)\end{array}$ & $\begin{array}{c}20,6 \% \\
(17,8 \text { a } 23,4)\end{array}$ & $\begin{array}{c}17,2 \% \\
(14,6 \text { a } 19,8)\end{array}$ & $\begin{array}{c}14,5 \% \\
(12 \text { a } 17)\end{array}$ \\
\hline $\begin{array}{l}\text { Náuseas y vómitos } \\
\text { luego de las 24 horas }\end{array}$ & $67(8,5 \%)$ & $57(7,3 \%)$ & $62(7,9 \%)$ & $38(4,8 \%)$ \\
\hline Hipotensión & $62(7,9 \%)$ & $74(9,5 \%)$ & $88(11,3 \%)$ & $113(14,3 \%)$ \\
\hline
\end{tabular}

\section{Conclusiones}

El agregado intraoperatorio de $50 \mathrm{mg}$ de metoclopramida a $8 \mathrm{mg}$ de dexametasona, es una forma efectiva, segura y económica para prevenir las náuseas y vómitos postoperatorios. La administración de $25 \mathrm{mg}$ de metoclopramida seguida de profilaxis postoperatoria puede ser una opción efectiva en aquellos pacientes de alto riesgo en quienes se intenta minimizar los efectos adversos.

Palabras claves: náuseas, vómitos, dexametasona, metoclopramida, profilaxis antiemética.

Key words: nausea, vomiting, dexamethasone, methoclopramide.

Fuente de financiamiento: Merck Kga, Darmstad ,Alemania y Ratiopharm, Ulm. Conflicto de intereses de los autores: No declarados

\section{Comentario}

Las NVPO son uno de los efectos adversos más frecuentemente relacionados con la cirugía y la anestesia (20 a $30 \%$ de los procedimientos). Si bien su impacto en la salud del paciente es bajo porque raramente implican un aumento de la morbimortalidad, ocasionan molestias y malestar en el paciente y retrasos en el alta. Hasta el momento, la evidencia acerca de la eficacia de la metoclopramida para la prevención de las NVPO era controvertida. Si bien la asociación de $10 \mathrm{mg}$ de metoclopramida con $8 \mathrm{mg}$ de dexametasona es ampliamente utilizada en diferentes centros esta dosis parece ser subóptima. La administración de 50mg de metoclopramida sería la dosis más efectiva y demuestra además reducir los vómitos en la fase tardía. En aquellos pacientes considerados de riesgo, utilizar 25mg de metoclopramida, con $8 \mathrm{mg}$ de dexametasona parece ser igualmente efectivo y con menores efectos adversos.

Al administrar metoclopramida es importante tener presente que, dada su vida media, conviene indicarla 30 a 60 minutos antes de finalizar la anestesia y no durante la inducción de la misma ${ }^{2}$.

\section{Conclusiones del comentador}

La administración intraoperatoria de 25 a $50 \mathrm{mg}$ de metoclopramida junto con $8 \mathrm{mg}$ de dexametasona es efectiva, segura y económica para prevenir las NVPO.

Ver glosario

Susana Pérez [ Servicio de Anestesiología, Hospital Italiano de Buenos Aires. ]

Pérez S. La combinación de metoclopramida y dexametasona es segura y eficaz para la prevención de las náuseas y vómitos postoperatorios. Evid. actual. práct. ambul; 10(3):69 May-Jun 2007. Comentado de: Wallenborn J, et. al. Prevention of postoperative nausea and vomiting by metoclopramide combined with dexamethasone: randomised double blind multicentre trial. BMJ 2006 Aug 12;333(7563):324. PMID:16861255

Referencias

1. Apfel C et al. A factorial trial of six interventions for the prevention of postoperative nausea and vomiting. N Engl J Med 2004; 350: 2441-51.

2. Maddali M, et al. Postoperative nausea and vomiting in diagnostic gyneacological laparoscopic procedures: comparison of the efficacy of the combination of metoclopramide and dexamethasone with that of dexamethasone and ondasentron. J Postgrad Med 2003;49:302-6. 